\title{
THE
}

\section{Improving labour relations performance using a Simplified Drum Buffer Rope (S-DBR) technique}

Satya S. Chakravorty

Douglas N. Hales

University of Rhode Island, dhales@uri.edu

Follow this and additional works at: https://digitalcommons.uri.edu/cba_facpubs

The University of Rhode Island Faculty have made this article openly available.

Please let us know how Open Access to this research benefits you.

This is a pre-publication author manuscript of the final, published article.

Terms of Use

This article is made available under the terms and conditions applicable towards Open Access Policy Articles, as set forth in our Terms of Use.

\section{Citation/Publisher Attribution}

Chakravorty, S. S., \& Hales, D. N. (2015). Improving labour relations performance using a Simplified Drum Buffer Rope (S-DBR) technique. Production Planning \& Control: The Management of Operations, 27(2), 102-113.

Available at: http://dx.doi.org/10.1080/09537287.2015.1079744 


\title{
Improving Labor Relations Performance Using A Simplified Drum Buffer Rope (S-DBR) Technique
}

\author{
Satya S. Chakravorty \\ Department of Management and Entrepreneurship \\ Michael J. Coles College of Business \\ Kennesaw State University \\ 1000 Chastain Road \\ Kennesaw, GA 30144, USA \\ schakrav@kennesaw.edu \\ 770.423 .6582
}

Douglas N. Hales*

College of Business Administration

The University of Rhode Island

321 Ballentine Hall, 7 Lippitt Road

Kingston, RI 02881, USA

dhales@uri.edu

401.874.7882

*Corresponding Author 


\section{Improving Labor Relations Performance Using A Simplified Drum Buffer Rope (S-DBR) Technique}

The purpose of this research is to describe an implementation of Simplified Drum Buffer Rope (S-DBR), a scheduling methodology under Theory of Constrains (TOC), in service operations of a U.S. military base. In doing so, this research contributes in two ways. For practitioners, this research is the first to show how S-DBR methodology can be utilized to improve the performance of labor relations. For academicians, this research is one of only a few to address the how questions of S-DBR use in a service context.

Key Words: Simplified Drum Buffer Rope (S-DBR), DBR, TOC, Service Operations 


\subsection{Introduction}

The United States Congress established the Base Realignment and Closures (BRAC) commission to make recommendations for optimizing military installations. BRAC evaluates military bases on competitiveness such as delivery, quality, and labor (relations); and makes recommendations for base closures and realignment (Ewing, et al. 2006). Previous rounds of BRAC recommendations have resulted in a total of 119 base closures and realignment of 87 infrastructure functions (Otal and Melhuish, 2013). Through the tool of public law, the United States Congress is likely to mandate the next BRAC in the year 2017. Given the real possibility of closures, it is imperative for each military base to justify its value and efficiency to the defence of the U.S. A key determinant is the labor relations efficiency of base operations. Due to its recent annual reviews, a military base in the southern U.S. - hereafter referred to as the 'Base' - was aware that its labor performance was historically worse than bases located in other parts of the country. Specifically, the Base's employee/management conflict resolution time, part of its labor relations performance measures (e.g. time to resolve grievance issues and execute disciplinary decisions) was not competitive when compared with similar bases. The Base's performance averaged 30 days over the 12 months of FY 2013, while several similar bases in the north and west were achieving 10 - 20 days. In order to increase competitiveness, the Base tried improvements from various internal and external sources since 2010. All of the programs had either worsened performance or achieved marginal success. A program begun in January 2014, based on a Simplified Drum Buffer Rope (S-DBR) control system finally led to improved performance from a mean of 30 to 10 days. This made the Base one of the best in the system for labor conflict resolution time.

S-DBR is one scheduling methodology developed under Theory of Constraints (TOC) principles that emphasizes the control of execution or job release into the system as a mechanism to improve performance (Schragenheim, et al., 2009). The purpose of this research is to describe how the S-DBR implementation improved labor relations performance. This paper extends the use of S-DBR to a new service area and application not in extant literature. It is unique in that while many researchers have conceptually argued that S-DBR is a viable option for a variety of service or manufacturing operations (Chang and Hwang, 2011). In fact, some have argued that the concept of effective controlled release can save lives. For example, early in 2014, many U.S. veterans died waiting for medical care because the Veteran Administration (VA) 
Hospitals administrators failed to control the release of critical cases for urgent medical care, thus clogging the system (Cooper, 2014). While our case study is not lifethreatening, it does affect employment for thousands of workers through improved labor relations. However, there is a paucity of research answering how it works in services. In doing so, this research contributes in two ways. First, for practitioners, this research describes how S-DBR can be implemented in service operations, specifically to improve labor relations. Second, for academicians, this research answers the how questions important to extending theory to a new area.

In the next section, we provide a brief literature review of TOC principles and SDBR characteristics. In sections three and four, we provide a description of the methodology and field experiment for S-DBR implementation. In section five, we write our implementation experience (or case study) and, in section six, we provide results of the implementation. In section seven, we provide implications of our implementation experience including conclusions from this study.

\subsection{Literature Review}

\subsection{Theory of Constraints (TOC) Principles}

More than 30 years ago TOC was a controversial development by Eli Goldratt as theoretical underpinnings for his Optimized Production Technology (OPT) software which he used as a shop floor control mechanism. TOC gained popularity after the publication of two books namely - 'The Goal' (Goldratt and Cox 1984), which delineated the basic principles of TOC and, subsequently, 'The Race' (Goldratt and Fox 1986), which described the DBR methodology. Over the years an interest in applying DBR has steadily grown among researchers that helped define the contexts in which it is most successful (e.g., Umble and Srikanth, 1990; Darlington, et al., 2014). TOC works by identifying an internal constraint (or Capacity Constraint Resource - CCR) in a process and then uses a DBR control methodology to manage work flow through the process based on the capacity of the constraint. An important concept in DBR is the presumed existence of a constraint on which to optimally manage the work flow. However, Rahman (1998) finds that not all processes contain internal constraints on which to base DBR. For these organizations the constraint on throughput is external, i.e. customer demand. For these situations, Schragenheim and Dettmer (2000) proposed Simplified -DBR, which is a variation of DBR, but still anchored in TOC principles. 
See Schragenheim (2010)'s work for an extensive discussion of the differences between DBR and S-DBR methodologies.

\subsection{Simplified Drum Buffer Rope (S-DBR)}

The application of S-DBR is intended to control process flows in systems where there is no internal bottleneck, but instead the constraint is external customer or client demand. This differentiates it from DBR which assumes an internal constraint. While many authors (e.g., Simons and Simpson, 1997; Goldratt, et al., 2002; Schragenheim, et al., 2009) have conceptually described S-DBR, there is a paucity of research empirically testing real-world implementations for how it works. For this reason, Goldratt (2006) developed a Strategy and Tactics (S\&T) tree to guide S-DBR implementation.For further information on the use of S\&T see Scheinkopf (2010).

According to Scheinkopf (2010), the S-DBR implementation consists of five elements: (1) Choking the Releases, (2) Managing the Priorities, (3) Dealing with Capacity Constraint Resource (CCR), (4) Load Control, and (5) Process Of On Going Improvement (POOGI) - i.e. systematically improving flow. S-DBR methodology utilizes Buffer Management (BM) concepts, which divide the time buffers into three regions namely Region I, II, and III. According to Chakravorty (2001), consumption of buffer in Region III is considered to be normal and no specific action is necessary; consumption of buffer in Region II implies jobs are somewhat late, monitoring is necessary, and consumption of buffer in Region I indicates that jobs are late and expediting is necessary. Limited in the service literature, Huang et al. (2011) demonstrates the S-DBR implementation in production operations. This study is unique because it is the first to examine an S-DBR implementation in the context of service operations to improve labor relations performance. This extends the use of S-DBR to a new area to solve a unique problem.

According to Schragenheim and Dettmer (2000) S-DBR is appropriate when,

1) Failure to meet the existing demand on the system will result in decreasing future demand. This applies to the Base since a department can’t meet current demand, they will soon be out of business.

2) There is no internal constraint in the system - instead the constraint is external, i.e. there is unused internal resource capacity that can handle existing demand. This differs from DBR where true internal constraints are assumed. This applies to the grievance resolution process because the current capacity can meet demand, 
3) Small changes to process routing will not create a capacity constraint on any resource. Since no labor reduction will take place, the existing capacity will be maintained and the implementation of S-DBR, discussed later, did not create a constraint in the long-term, a quarter or a year.

4) The planned load is assumed to be within the capabilities of existing resources, i.e. you don't intentionally plan to overload the system. The S-DBR is designed to match capacity with demand and not overload the system.

In short, S-DBR sets the external demand as the Drum, and the Rope signals a release of a new case to a LR or SR specialist only as a case is completed. In DBR, an internal constraint (internal Drum and Rope) controls the release. As a side-note, the Base had tried using Lean, Six Sigma, and DBR to address the labor resolution problem, but they did not work either practically or conceptually. Conceptually they failed because they are focused on eliminating waste and increasing the capacity of internal processes, which is not true of DBR. Since the internal capacity of the labor resolution processes were sufficient these programs led to no improvement in resolution time.”

\subsection{Methodology}

\subsection{Case Study}

Since S-DBR has not been previously applied to improve labor relations performance, and labor relations conflict time is a key indicator of Base labor performance used by BRAC (Wright, et al, 2006), a case study examining the possible effects is appropriate. The case describes the six-month implementation of S-DBR to answer how it worked to improve labor relations performance in a service context. While many conceptual, simulation, and analytical studies describe what S-DBR is and model where and when it works, none describe how it works in a service context to improve the labor relations process. According to Childe (2011) case studies are appropriate for extending theory or application to a new context. Childe also emphasizes the need for research to be practical, which requires explanation of how a theory works to practitioners. In this case, S-DBR is important because poor labor relations performance can contribute to the Base's higher risk for closure, with a corresponding loss of jobs and economic vitality for the region. 


\subsection{The Base}

The Base has over 18,000 unionized employees and military personnel working in two departments, Maintenance and Support, performing various vehicle, general equipment, and electronics maintenance functions for a variety of military operations. The Maintenance department is divided into, a) vehicle maintenance group (AMXG), b) commodities maintenance group (CMXG), and c) electronics maintenance group (EMXG). The Support department is responsible for directing essential base operations such as security, vehicle management, fuel, and plant services. A majority of the Base's employees are described as "skilled" workers and are represented in collective bargaining by the American Federal Government Employees (AFGE) Union - hereafter referred to as the 'Union'. As part of the collective bargaining agreement, the Base maintains three labor relations offices that collect and process conflicts between the Base command structure (management) and labor. The offices house labor relations specialists who handle a variety of conflicts.

\subsection{Data Collection}

The data for the case study was collected in a participant-observer manner (Yin, 2013), where the researchers not only observed each activity in the study but also led the early stages of the S-DBR implementation system-wide, before the program was assigned to the supervisors. First, the organizational structures for the Maintenance and Support departments are diagrammed, with descriptions and job titles of all personnel involved in the labor relations process. This shows the chain of command and string of approvals necessary to complete a labor action. Second, a spaghetti-diagram is used showing the work flow and documentation involved in the process. A spaghetti diagram is a Six Sigma tool used to graphically visualize actual flow through a process, rather than what it should be or is estimated to be. "It is a snapshot in time so it may not include all whatif and special scenarios.” (www.six-sigma-material.com; page 1) Third, descriptive statistics are collected on the flow-time data for processing and completing a labor grievance case under both experimental conditions and eventual performance results for the case study.

\subsection{Labor Relations Process}

The Base employs two types of specialists to handle three categories of labor issues involving employee/management conflicts; namely Labor Relations (LR) specialists 
who handle only grievance cases, and Employee Relations (ER) specialists who handle only disciplinary cases, and some miscellaneous cases (e.g., Congressional Inquiries or Inspector General Complaints). A grievance is an employee complaint of unfair treatment, a breach of collective bargaining agreements, a misapplication of law, or a condition-of-employment violation. Generally, disciplinary action is seen primarily as a corrective measure, aimed at preventing further misconduct or poor performance. The most common types of disciplinary action are warnings, and in serious cases, dismissal; however, disciplinary action can sometimes mean suspension from work, or the removal of certain privileges, or, in rare instances, demotion. To be lawful, disciplinary action or dismissals must be fair and reasonable.

\subsection{Labor Relations Challenges}

The Base processes labor relations grievance claims using a process this study refers to as Scenario 1. Scenario 1 represents the current labor case practice where a LR or ER specialist handles multiple cases at once, working on as many four-five cases simultaneously, with an additional 20 or so in queue. The Base has many challenges when trying to execute grievance and disciplinary cases using Scenario 1, which include a complex organizational structure, convoluted work flow, and inefficient work handling. Complex organizational structures include physically separate buildings for basic functions (Figure 1). Under the Maintenance Group Commander, there is a Civilian Personnel Office (CPO) which maintains two separate offices in different locations to perform identical LR and ER activities. Under the Support Group Commander, there is a single Management Support (MS) office, which handles both LR and ER cases. Also, the MS office assigns management representatives, known as Designated Management Official (DMO), to different groups such as AMXG or CMXG. With two commanders and layers of management in between, with three supervisors; it is a difficult environment for sound and timely labor conflict resolution. The situation is further exacerbated because the three offices are located in different buildings. For the most part the specialists working in these offices work independently with little or no interaction, creating a propensity to make locally optimal decisions that benefit one office, in deference to the others. There is no encouragement to cooperate to seek solutions which can benefit the Base as a whole. In addition, there is no interactive learning (cross-training) among LR and ER specialists, which harms their promotion opportunities because they are unaware of activities in other departments. 
(Insert Figure 1: Organizational Structure)

After a grievance or disciplinary case is filed, they are processed in a convoluted work flow, meaning that there is little standardization in completing virtually identical tasks. A spaghetti diagram showing representative work flow is shown in Figure 2. The diagram shows, for example, at AMXG the DMO typically receives disciplinary or grievance cases first. Immediately, the disciplinary case is forwarded to the ER office and a grievance is forwarded to the MS office. At times, DMO may instead forward the case to LR office (to begin step 1). While coordinating with AFGE, the LR office may send the case back to the DMO. At other times, the LR Office, after completing step 2, sends the case back to MS. As the diagram shows, there is no apparent benefit to having different work flows and standardizing tasks should lead to improved performance. Instead, documents are handled multiple times through the same office, and often returned and rerouted after no action is taken. As the work flow varies among the different offices some cases are lost, causing further delays. Significant delays can be very costly, frustrating the employees who must show daily progress on each case, and embarrassing to the Base through poor labor relations and delayed case resolution time. In addition, labor relations with the LR and ER specialists are also affected because the convoluted work flow causes an imbalance in workload among the offices. In other words, one set of specialists may have too many cases and thus struggle to make, deliver and execute decisions, while other specialists have little to do. Since the offices are physically separate, there is no cross-training or visibility of workload to commanders or supervisors thus making it difficult to fairly balance workload among the offices even when the opportunity arises.

(Insert Figure 2: Resolution Process Flow)

Due to the multiple 'touches' required by each specialist and office, inefficiency in handling cases is created. In Scenario 1 LR or ER specialists are assigned cases as soon as they arrive to the office - clogging their inboxes with an average of 20 cases per specialist in queue at any given time (Mean $=19.8$, Std Dev $=4.5$ cases, Range $=0$ 35). This creates the need to multi-task across cases to show progress on each one, which according to Lindbeck and Snower (1996) reduces efficiency. This inhibits a 
commander's ability to track progress on any case and delays their ability to render a decision and thus harms the Base’s labor relations performance.

\subsection{The S-DBR Implementation - Case Study}

The Base agreed to implement the S-DBR mechanism to control the release of grievances to the specialists. In doing so, the commander made three key policy changes that 1 ) allowed the researchers to co-locate all specialists in a single office, 2) allowed the researchers to control the release of cases to the specialists and 3) eliminated the requirement for specialists demonstrate daily progress on each case. This study refers to the revised process as Scenario 2. It is important to note here that prior to S-DBR the Base tried many techniques over the years to improve labor relations performance, but were unsuccessful in either achieving improvement or sustaining an improvement after a few weeks. Some popular approaches included basic TOC/DBR, Lean, and Six Sigma, among others. Please refer to Womack and Jones, (2003) for a detailed description of Lean tools and Pyzdek and Keller (2009) for Six Sigma tools. Some reasons for the failure of these programs are not directly applicable to the S-DBR implementation but some relevant findings related to their failures are discussed later in this study. One issue with previous efforts that weighed in the Base's decision to perform a full roll-out of S-DBR include the commander's willingness to try a unified effort across all three offices. Previous efforts were ran by individual offices, so consequently the offices rarely worked together to integrate efforts. One objective of the implementation is to try the same S-DBR method across all offices and specialists at the same time so that synergy can develop and specialists can support and learn from each other. The next section of this study describes How S-DBR was implemented, including the preliminary activities to fulfil the assumptions necessary for using S-DBR.

\subsection{Specialists \& Office Reconfiguration to Support S-DBR}

The implementation progressed in four distinct phases. In the first phase, the focus was on the training of the ER and LR specialists on the Scenario 2 method and the basics of S-DBR. In the second phase, the workflow was analyzed and a new process and cellular configuration was developed to process cases to support the S-DBR. In the third phase, the three offices were physically relocated to a single location to support a cell structure for the specialist's work flow. In the fourth phase, the S-DBR mechanism was implemented to control workflow to the cells. At first, the researchers managed the 
release of cases to the service cells, then the supervisors took over and the researchers only observed the process.

To improve the acceptance of the new system among specialists and their supervisors, the Base commander requested that all employees affected by the change to participate in a one-day training on the basics of Constraint Management and specifically S-DBR and how it should improve their work performance. During this training phase, much of the statistical and analytical components were excluded because the authors found that the majority of the specialists did not possess the background or the academic preparation to fully understand such tools. Instead, the authors used many training techniques including illustrations, examples, and interactive simulation games to provide practice in the basics of the S-DBR process that have shown to be effective by other researchers (e.g. Chakravorty and Verhoeven, 1996). Essentials of the training program included the five focusing steps of TOC, DBR, and Buffer Management, concept of the 7-wastes, process and value-stream mapping, and applying a five-step scientific method of problem-solving including: a) identify the problem, b) gather and analyze information, c) generate alternative solutions, d) prioritize and implement the best solutions, and e) follow-up to ensure it worked. This approach is similar to Six Sigma's approach of define, measure, analyze, improve, and control; and Lean's plan, do, check, act; among others. During the training, specialists interacted for hours, developing strategies (e.g., ideas to eliminate multi-tasking), simulating work flow, and then the authors discussed how these strategies are applied to improve labor relations performance.

In the second phase the analysis showed that based on the workload there was no internal constraint, and therefore the S-DBR implementation was justified. However, it is important to note here that while the grievance resolution times were artificially truncated to the closest quarter-hour there is variety among the times because a grievance can be filed for a number of reasons, with each case resulting in a different cycle time. For example, grievances can be filed for hundreds of issues ranging from trivial verbal reprimands to serious issues such as harassment or termination-for-cause. Resolutions can often take less than an hour or several days and weeks, depending the process and potential impact. The analysis revealed that approximately $75 \%$ of the workload consisted of grievances/discipline cases, and about $25 \%$ of the remaining workload consisted of miscellaneous cases, such as Congressional inquiries or Inspector General (IG) complaints that were often expedited. In the Base, a cell was developed 
to handle the grievance and disciplinary cases called a "service cell” and a second cell type was developed to handle the miscellaneous cases called a "specialized cell." Each service cell included one LR specialist and one ER specialist so that all cells can handle both grievance and discipline cases. Training and practice was provided on the role of each specialist in a cell, as well as how the concept of a Scenario 2 service cell differs from their traditional practice. The intent is for the LR and ER specialists to cross-train each other so that over-time flexibility is improved, where either LR or ER specialists can perform both duties and assist in managing peak workload. Considering the existing workload and expertise of individuals in the three offices, 10 service cells are required. One larger specialized cell with three-five specialists can handle all of the typical miscellaneous cases. Figure 3 shows the cell organization.

In the third phase, the offices were relocated to a cellular configuration that supported the model in Figure 3. All LRs and ERS were relocated to one central building, and then the two specialists were chosen for each cell based on skills and seniority.

(Insert Figure 3: Service Cells)

In the fourth phase, the S-DBR control was implemented. The reporting structure is narrowed by reducing the number of supervisors from three to two. The two who were selected had previously worked as successful LR and ER specialists and had received supervisory training at the Base. The third supervisor is no longer needed since all specialists are in the same office. The structure is then flattened so that the supervisors report directly to the Deputy Commander of the Support department; who reports directly to the Commander. The old structure included individuals that are in the chain only for 'information purposes' and not approvals, but because the workflow in Scenario 1 is sequential, cases are delayed waiting for mere notification sign-offs, and not for value-added activities such as approvals or content reviews.

S-DBR also requires a buffer management system, which is typically managed in manufacturing through information technology. A range of options for information technology was considered but the specialists suggested using Microsoft Excel. A decision was made to designate an individual specialist responsible for managing the buffer with daily input from the supervisors. The S-DBR implementation followed five of the elements 4.1.1 - 4.1.5. In the labor resolution process, the buffer exists to ensure 
that the specialists are busy on cases that are prioritized by the Base commander, and to ensure that the cells remain busy with relevant cases. Because there are several cells, routings can occasionally vary based on a specialists expertise, again justifying the use of a buffer.

\subsubsection{Choking the Release}

To prevent multi-tasking the Base eliminated its policy of requiring specialists to work on each case daily. Instead of relying on the specialists to choose the cases - which encourages multi-tasking, the S-DBR system uses input control - where a single case is assigned to a specialist until it is completed. This is called controlled release, versus a non-controlled release as seen in Scenario 1 where cases pile-up in specialists inboxes as they arrive. The implementation of controlled-release began with entering cases into an Excel spreadsheet. Each case is assigned a due date and ordered in the Excel sheet based on the type of grievance and expected resolution time. Occasionally the Base commander will select cases for higher priority. The cases are released to a LR/SR specialist cell which manages the case until completed. Simple grievances can often be completed quickly, and most cells have slack time sufficient to prevent a case from missing its due date. During low demand periods, the cases are normally released quickly, but during peak periods, the cases may stay in the buffer for the full term.

Controlled release requires four steps. Step one is setting the buffer size. The average time to complete grievance/disciplinary cases is 30 days. To avoid consequences of missing deadlines, specialists artificially added slack to each intermediate step of grievance/disciplinary process. This ensured that the deadlines were not tightened which would make the specialists jobs more difficult. With no historical data to guide them, the commanders arbitrarily set a buffer size of 50\%, meaning that with typical demand, where no buffer was consumed, a case should be complete in 15 days. This is considered an aggressive and somewhat impractical target, because the number of submitted cases can vary widely from day-to-day, making it impossible to consume the buffer in higher demand periods. As discussed before, a key performance measure is the time to resolve labor conflicts, which is correlated with the cost and resources involved. Because of this, it is essential that the Base decrease the time to deliver and execute resolutions in less than 30 days.

The second step in controlled release involves generating a release schedule of cases to maintain the targeted buffer sizes. Generally, the release follows a First-In- 
First-Out (FIFO) priority rule; however, supervisors frequently assign higher priority to some cases that potentially have high impacts. For example, some labor issues affect only one worker, while other disputes may affect a whole department.

The third step in controlled release is enforcing the release schedule. LR and ER specialists can circumvent the S-DBR system for their own benefits if not constrained. For example, if left to their personal preferences, employees can choose the easier cases to work on (a.k.a. cherry picking), instead of following FIFO. Supervisors can also circumvent the system through favoritism, by assigning easier or more visible cases to preferred specialists instead of fairly balancing the workload across service cells. Some service cells can get overloaded, causing unnecessary delays, while others become starved.

The fourth step is freezing excessive WIP (limiting cases in process) to prevent clogging the system. It is possible that supervisors can release cases early ahead of schedule to fill available capacity during low demand periods - when some cells aren't busy. But when released early the queues fill quickly, and once demand picks up the cells again become congested with incomplete cases. Case resolution time again increases and labor relations performance drops, forcing the specialists to again multitask to show progress. To prevent this in S-DBR, cases must be released only in the order established in the buffer to ensure that multi-tasking and load imbalance does not occur. This decision was received by the service cells with mixed feelings.

Traditionally overloaded specialists are pleased that their workload will decrease, but under-loaded specialists are apprehensive because their workload will likely increase. Now that service cells have both LRs and ERs, any cell can process virtually any case.

\subsubsection{Managing the Priorities}

Managing priorities refers to the sequencing of cases to be released to the cells. Both the FIFO and expedited cases must be tracked and released according to established priorities. It is important to remember that over the course of a quarter there was no internal constraint after the specialist cells were created; therefore, in low and typical demand periods cases are released quickly to the cells, limiting the benefits of the buffer. However, during heavier demand periods the demand temporarily exceeds the capacity of the cells, increasing the buffer, and creating capacity constraint resources (CCRs). The buffer becomes congested, thus creating the need to use controlled release. A number of issues can create spikes in demand including filing deadlines, statues of 
limitations, and expedition by commanders. During the peak periods, the buffer prevents clogging the cells.

The Base accomplished the objectives of managing priorities in two steps. First step was to establish buffer zones to implement priorities. That was accomplished by dividing the 15 day buffer into three regions from low, medium, and high priority typically labelled Region III, Region II, and Region I. In order to update the buffer, the supervisors held a buffer meeting at 9:00 AM daily. The supervisors released the highest priority cases to the cells first, then the cases with the earliest submission dates. Only then were the lower cases released - still one-at-a-time. This ensures that the workload is reasonable and fair and as a result the method used to evaluate specialist's performance was revised. Under Scenario 1, specialists were evaluated on criteria that had no relationship to the labor relations resolution time used for the Base. Instead, they were evaluated based on trivial items such as the number of mistakes on paperwork (mostly minor in nature), their tardiness and lateness records, etc. These criteria were not only unrelated to the resolution time performance, but also harmed the morale of the units, some of the LR and ER specialists to file labor grievances. For example, even though all service/specialized cell members worked a full eight hours/day, the supervisors spent most of their time tracking and documenting trivial infractions. This includes being 10 minutes late to work or taking an extra 13 minutes for lunch, etc. Once incurred, the specialists were consistently reminded of these infractions. Even when there was a lower case load, specialists were afforded no job flexibility; however, when their case load was higher thus requiring them to work through breaks or lunch supervisors gave no credit toward their performance.

The second step is sustaining management through the new buffer protocols. During spikes in demand the buffer becomes congested which results in a propensity among the supervisors to revert back to the old system - to flood the cells with cases to keep specialists from being idle. They were afraid of being perceived as not doing their job if workers don't stay constantly busy - a traditional concept long refuted by Deming (1986) and Goldratt and Cox (1986). This frustrated the cell members and seriously harmed morale. The Base commanders had to openly support the new buffer protocol and consistently reinforce it with the supervisors. They began participating in many of the service/specialized cell activities and finally developed operating principles for managing the cells. After two months, the situation gradually improved and supervisors strictly followed the buffer rules. If a case is placed in Region I, implying 
that it is late or immediate action is necessary, the supervisor can shorten breaks, schedule overtime or, contact other departments for temporary assistance.

Occasionally, since the supervisors had ER and LR experience, they directly provided necessary assistance to the service cell and expedited the completion of the case.

Otherwise, they were flexible with work schedules and did not penalize the specialists for minor infractions.

\subsubsection{Dealing with CCR}

In the TOC literature, a temporary bottleneck called a Capacity Constraint Resource (CCR) can develop. A CCR is harmful because it's a short-term bottleneck that inhibits flow that is difficult to detect a priori. A CCR requires immediate corrective action or performance can quickly deteriorate. In this S-DBR implementation the legal department is the CCR. An analysis revealed that during heavy case loads the legal department got behind, which delayed all downstream processes. Traditionally, the staffing of the legal department was determined based on the average yearly demand instead of peak periods, and cases were processed based on FIFO. Since the buffer schedule to the service cells does not consider the variety in legal requirements, the FIFO priority rule did not work well. The legal department became overwhelmed with cases and reached out to their counterparts on other bases for temporary assistance. The Base decided to modify the release schedule for all the cases to include the legal department. For typical cases, the FIFO rule was still employed, but not for expedited cases. To alleviate the issue during peak demand, he Base added two additional legal experts, and thus the department rarely experienced CCR status, which is an important assumption in S-DBR.

\subsubsection{Load Control}

In order to implement a successful S-DBR implementation the work load needs to be monitored and adjusted each morning to ensure the cells are working on the highest priority cases first.. The purpose is to ensure that the system is not overloaded. Due to the seasonality in case loads, supervisors had some visibility of peak demand. For example, following the labor appraisals in January, there is an increase in the number of grievance cases filed in February and March by workers who feel that they are unfairly treated. During the daily buffer meetings in March 2014 however, the supervisors discovered that there was an unusually large increase (about 35\%) in grievance cases 
which could not be handled with the existing cell capacities. The commander discovered that other Bases were more proactive in preventing labor conflicts from becoming formal grievances. For example, when maintenance workers are dissatisfied with their annual appraisals they can file an informal grievance with Human Resources (HR). The maintenance supervisor has 10 business days to respond to the grievance and either satisfy the worker without further action or allow a formal grievance to proceed. If the employee is satisfied, then their complaint does not become a formal grievance. No harm is done to labor resolution time performance. If the employee is not satisfied, only then does the complaint become a legitimate grievance case, and required to be forwarded to a service cell. Some Bases acted more proactively by establishing personal relationships between HR, management, and labor representatives thus preventing many disputes from becoming grievance cases.

\subsubsection{POOGI - Systematically Improving Flow}

The POOGI improvement program was implemented with the buffer management system. Every two weeks, the supervisors performed Root Cause Analysis (RCA) (Pyzdek and Keller, 2009) to pinpoint improvement opportunities. Root Cause Analysis is a traditional method used in many programs to discover the cause of an observed phenomenon - for the purpose of controlling/influencing the phenomenon. For example, for processes consuming too much of the buffer, a group of service cells developed a process map of disciplinary cases. The longest non value-added activity is in the legal department, where the cases are placed in queue until an attorney is available to review and make a recommendation. During peak periods when the legal department was a CCR, the time in queue represented $80 \%$ of the total process time.

In addition to TOC and S-DBR, over time, a variety of tools were taught to managers, supervisors, and service cells, including Six Sigma (Pyzdek and Keller, 2009), and Lean Methods (Deming, 1986). Several specialists earned their Six Sigma Green Belt. The supervisors along with service cells applied a common Lean tool Statistical Process Control (SPC) - to the throughput of cases, and found two cells that were under performing. The results of a Cause/Effect diagram found that these service cells were unhappy with the changes and were subsequently moved to another office.

\subsection{Results of S-DBR Implementation}

This section describes How S-DBR led to improved labor resolution time. 


\subsection{Tangible Benefits}

S-DBR demonstrated a 37.5\% decrease in the elapsed time to process a labor resolution case. Following the S-DBR implementation across all specialists, the timeline to render decisions on discipline/grievances cases dropped from an average of 30 days to 10 after the first six months, a drop of $66.7 \%$. The monthly standard deviation is 4.5 days. This suggests that S-DBR can improve service operations as it does in manufacturing.

There are two primary reasons explaining how the program improved labor resolution time; first, the S-DBR allowed supervisors to control the work flow, to sequence cases to the specialists based on submission date or case priority. Releasing cases based on FIFO logic from the buffer limited the cherry-picking opportunities, the build-up of cases at the specialists work stations, and the unbalanced work flow. Supervisors can track progress on each case to ensure they are processed in a timely manner and specialists can focus their efforts on a single case until it is resolved, thereby eliminating multi-tasking. Second, an unexpected result is that after six months of implementation the number of grievance cases dropped by 22\%. Follow-up interviews gave three primary reasons for the drop in cases; a) the S-DBR effort and its possible benefits to keep the Base open increased the attention given to the labor relations process, i.e. the Base leadership signals they care about improving labor relations; b) the faster grievance resolution time improved overall labor satisfaction, where there is less informal, i.e. grapevine, conversation centered on the long resolution time. This is important because BRAC, the board that recommends base closures, evaluates a decrease in the number of grievance cases as an improvement in organizational health; and c), due to the unbalanced work load on the specialists, they filed their own labor grievances. The improved control by the S-DBR had all but eliminated the workload imbalance and only two grievances from specialists had occurred during the six months. This contributed to the improved probability that the Base in the South can compete with the North and West if future closures occur. Anecdotally, it is possible that some of the improvement occurred because once the employees heard that the Base is evaluated based on its grievance resolution record, the fear of closure may have discouraged the number of grievances filings. 


\subsection{Implications for S-DBR Literature}

In addition to the practical benefits to the Base, the findings also have impacts on the SDBR literature. First, this case answers how 'Choking the Release' plays an important role in effectively managing service operations and quantifying its effect on performance. While over the years studies using conceptual, analytical, and simulation models shows the importance of controlled release in a number of contexts under titles such as 'input/output sequencing ', and 'input control' (e.g., Baker, 1984; Onur and Fabrycky, 1987). Reported benefits include reduced work-in-process, resource idleness, order tardiness, and shop floor congestion, among others (e.g., Fredendall, et al. 2010; Harrod and Kanet, 2013). The problem is that there is wide variance in reported analytical and simulated benefits, making it difficult to understand how a real organization can benefit.

The second implication is that, despite initial difficulties with practically applying S-DBR in services, violating the buffer rules leads to less visibility for work loads, inhibits a supervisor's ability to track progress, and allows congesting the work space with unresolved cases. The buffer rules require the visible and consistent support from top management. Field studies (e.g., Liker, 2004) point out that leadership’s commitment, and their routine participation, is necessary for sustained improvements. According to Schragenhiem and Ronen (1991), priorities based on the buffer rules synchronize various activities of operations, which improve their reliability performance. They view reliability as the degree to which current status becomes an accurate predictor of future performance. Recovery actions initiated based on prioritizing demand through buffers can be effectively utilized to protect performance of operations from unexpected uncertainties.

The next implication is that for S-DBR to be beneficial in services, CCRs must be present, else immediate release is just as effective. As temporary bottlenecks, CCRs benefit from buffers because Lawrence and Buss (1994) suggests that providing protective capacity at the non-bottlenecks (when they are not CCRs) is the "best hope" for improving the performance of such operations. Our study finds that CCRs can also be managed in services by making processes more flexible. More case studies are necessary to understand CCR's effect and how to effectively manage it to improve the performance of operations.

The fourth implication is that the load control function of S-DBR is more important than previously reported. With the $22 \%$ reduction in case load created by the 
residual benefits of the implementation in the Base, the time period that the cells became CCRs was reduced thus preventing overloading the system. While prices, etc. (e.g., Moodie, 1999) have been shown to control workloads in simulations, this is the first service study to demonstrate how S-DBR controlled the load in a non-consumer environment, when prices were not the driver of demand. There is a paucity of studies testing different strategies for load control to prevent overload situations in S-DBR in service operations.

The fifth implication is that POOGI was implemented for systematically improving the flow in a manner consistent with a continuous improvement process. Lean and Six Sigma did not improve its labor resolution process. Lean was helpful in recognizing obvious waste activities, but the implementation was slower than expected and the required training was going to take one-year to complete, plus another year to implement. The Base needed faster results. A Six Sigma program was also attempted, but the improvements implemented by the Black Belt personnel were not sustainable. As soon as the Black Belts left the LR and ER offices, performance would deteriorate and processes migrate back to the old system within a few weeks. This suggests that the success of improvement programs may be contextual, and not a one-size-fits-all approach will achieve results. For example, Chakravorty (2011) found that in an aircraft maintenance division that serviced landing gear, a Six Sigma implementation failed to achieve results; however, in another division that serviced interiors, Six Sigma achieved sustained improvement. This study supports the concept that proper sequencing and the controlled release of cases, or jobs in general, can have huge impacts on performance.

\subsection{Conclusions and Limitations}

In complement to empirical models that show the variables and the cause and effect relationships, case studies describe how the variables interact and why they work to achieve the desired results. The description of "how" the S-DBR resulted in lower resolution time is addressed in the results section. These include the preliminary activities to fulfill the assumptions of using S-DBR, including simplifying the reporting and departmental structure, and locating the specialists in close proximity to support a control mechanism that released cases based on external demand. It led to improved performance because unlike Lean, Six Sigma, and other methods that prevent internal bottlenecks, S-DBR managed the demand placed on the system. The organization now 
uses the S-DBR with other improvement efforts on the Base, often combining Lean and Six Sigma with S-DBR, which according to the commander has led to the salvaging of several improvement programs previously abandoned due to poor performance, which he refers to as the practice of Improvement Systems Recovery.

As with all real-world implementations, a number of issues arise when a process change is made that can confound the effects on the system (Hales, et al 2008). By definition, a field experiment can't be closed-form and isolated. This is a weakness of a field experiment. Part of the evidence that improvement actually occurred, due to the reasons specified, is that the stimulus comes before the effect, e.g. Hales, et al (2008). Therefore several activities could have indirectly contributed to the reported benefits of S-DBR including the consolidation of the offices, the reduction in the number of supervisors, and the creation of specialist cells that increased internal capacity. However, the reported reduction in resolution time did not occur until after the S-DBR control was added. These changes in offices, supervisors, and cells were not direct effects, but necessary to fulfil S-DBR assumption \# 2, which assumes no internal constraint or long-term CCR.

\section{References}

Atwater, J.B., Chakravorty, S.S., 1995. "Using the theory of constraints to guide the implementation of quality improvement projects in manufacturing operations." International Journal of Production Research, 33 (6): 1737-1760.

Baker, K.R., 1984. "The effects of input control in a simple scheduling model.” Journal of Operations Management, 4 (2): 99-112.

Chakravorty, S.S., 2011. “Natural Selection”, Quality Progress, 44 (10): 30-35.

Chakravorty, S.S., 2001. "An evaluation of the DBR control mechanism in a job shop environment.” OMEGA: The International Journal of Management Science, 29 (4): 335-342.

Chakravorty, S.S., Verhoeven, P.R., 1996. "Learning the Theory of Constraints with a simulation game.” Simulation \& Gaming, 27 (2): 223-237.

Chang, Y., Huang, W., 2011. "Using simplified drum-buffer-rope for re-entrant flow shop scheduling in a random environment.” African Journal of Business Management, 5 (26): 796-810.

Childe, S.J., 2011. “Case studies in operations management.” Production Planning \& Control. 22 (2): 195-219.

Cooper, A.H., 2014. Anderson Cooper 360: CNN News, February-April, New York, NY. (www.cnn.com)

Darlington, J., Francis, M., Found, P., Thomas, A., 2014. "Design and implementation of a drum-buffer-rope pull-system.” Production Planning \& Control, online, June, 01. 
Ewing, Jr. P.L., Tarantino W., Parnell, G.S., 2006. "Use of decision analysis in the army base realignment and closure (BRAC) 2005 military value analysis.” Decision Analysis, 3 (1): 33-49.

Fredendall, L., Ojha, D., Patterson, J., 2010. Concerning the theory of Work Load Control, European Jour. Of Operational Res., 201, (1),: 99-111.

Goldratt, E.M., Cox, J., 1984. The Goal. North River Press: Croton-on-Hudson, NY.

Goldratt, E.M., Fox, R.E., 1986. The Race. North River Press: Croton-on-Hudson, NY.

Goldratt, E.M., 2006. Reliable rapid response strategy and tactics tree.. North River Press, NY

Goldratt, E. M., Goldratt, R., Abramov, E., 2002. “Strategy and Tactics.” Goldratt Consulting.

Hales, D., Sridharan, V., Radhakrishnan, A., Chakravorty, S., Siha, S. 2008. Testing the accuracy of employee-reported data: An inexpensive approach to traditional methods. European Journal of Operational Research, 189: 583-593.

Harrod, S., Kanet, J. 2013. “Applying work flow control in make-to-order job shops.” Int'l. Jour. of Production Economics, 143: 620-626.

Huang, Y.L., Huang, C., Li, R.K., 2011. “Using simplified drum-buffer-rope to rapidly improve operational performance: A case study in China." Production and Inventory Management Journal, 47 (1), 80-93.

Lawrence, S.R., Buss, A.H., 1994. "Shifting production bottlenecks: Causes, cures, and conundrums.” Production and Operations Management, 3 (1): 21-37.

Lenort, R., Samolejova, A., 2007. "Analysis and identification of floating capacity bottlenecks in m Metallurgical production.” Metalurgica 46: 61-66.

Lindbeck, Assar and Snower, Dennis, 1996. "Reorganization of Firms and LaborMarket Inequality,” The American Economic Review, American Economic Assoc. Publishers, 86 (20): 315-321.

Liker, J.K., 2004. The Toyota Way, McGraw Hill, New York, NY.

Moodie, D.R., 1999. "Demand management: The evaluation of price and due date negotiation strategies using simulation.” Production and Operations Management, 8 (2): 151-162.

Onur, L., Fabrycky, W.J. 1987. “An input/output control system for the dynamic job shop.” IIE Transactions, 19 (1): 88-96.

Otal, C.A., Melhuish, W., 2013. "A model for realignment and consolidation: Applying BRAC principles to the federal financial management and system environment." The Journal of Government Financial Management, 62 (2): 20-26.

Pyzdek, T., Keller, P., 2009. The Six Sigma Handbook, McGraw-Hill, New York, NY.

Rahman, Shams-ur. 1998. "Theory of constraints: a review of the philosophy and its applications." International Journal of Operations \& Production Management, 18 (4): 336-355.

Scheinkopf , L.J., 2010. Thinking process including and S\&T tree. In J.F. Cox and J.G. Schleier, Jr., eds. Theory of Constraints Handbook, McGraw-Hill, New York..

Schragenheim, E., 2010. From DBR to simplified DBR for make-to-order. In J.F. Cox and J.G. Schleier, Jr., eds. Theory of Constraints Handbook, McGraw-Hill, New York.

Schragenheim, E. Dettmer, H.W., Patterson, J.W., 2009. Supply Chain Management at Warp Speed: Integrating the System from End to End. CRC Press, Boca Raton, FL.

Schragenheim, E., Dettmer, H.W., 2000. Manufacturing at Warp Speed: Optimizing Supply Chain Business Performance. St. Lucie Press, Boca Raton, FL.

Schragenheim, E., Ronen, B., 1991. "Buffer management: A diagnostic tool for 
production control.” Production and Inventory Management Journal, 32 (2): 74-79.

Simons, J.V., Simpson, W.P., 1997. “An exposition of multiple constraint scheduling as implemented in the Goal System (formerly Disaster)", Production and Operations Management, 34 (1): 3-22.

Umble, M.M., Srikanth, M.L., 1990. Synchronous Manufacturing. South-Western, Cincinnati, $\mathrm{OH}$.

Womack, J.P., Jones, D.T., 2003. Lean Thinking: Banish Waste and Create Wealth. Free Press, New York, NY.

Wright, P., Gardner, T., and Moynihan, L., 2006. "The impact of HR practices on the performance of business units.” Human Resource Management Journal, 13 (3): 21-36.

Yin, R.K., 2013. Case Study Research: Design and Methods, $5^{\text {th }}$ Ed., Sage Publications: Thousand Oaks, CA.

Figure 1. Organizational Structure

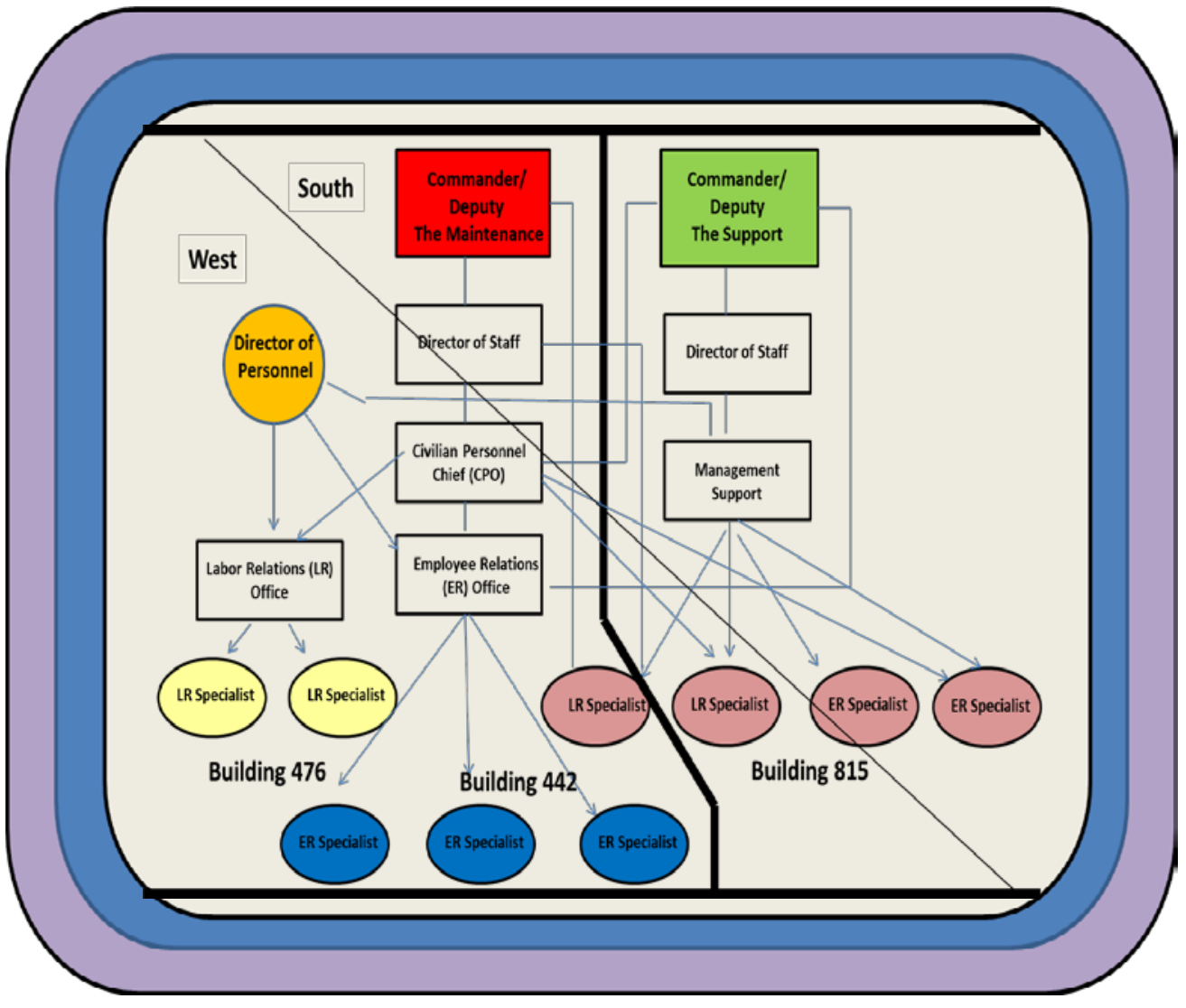


Figure 2. Resolution Process Flow

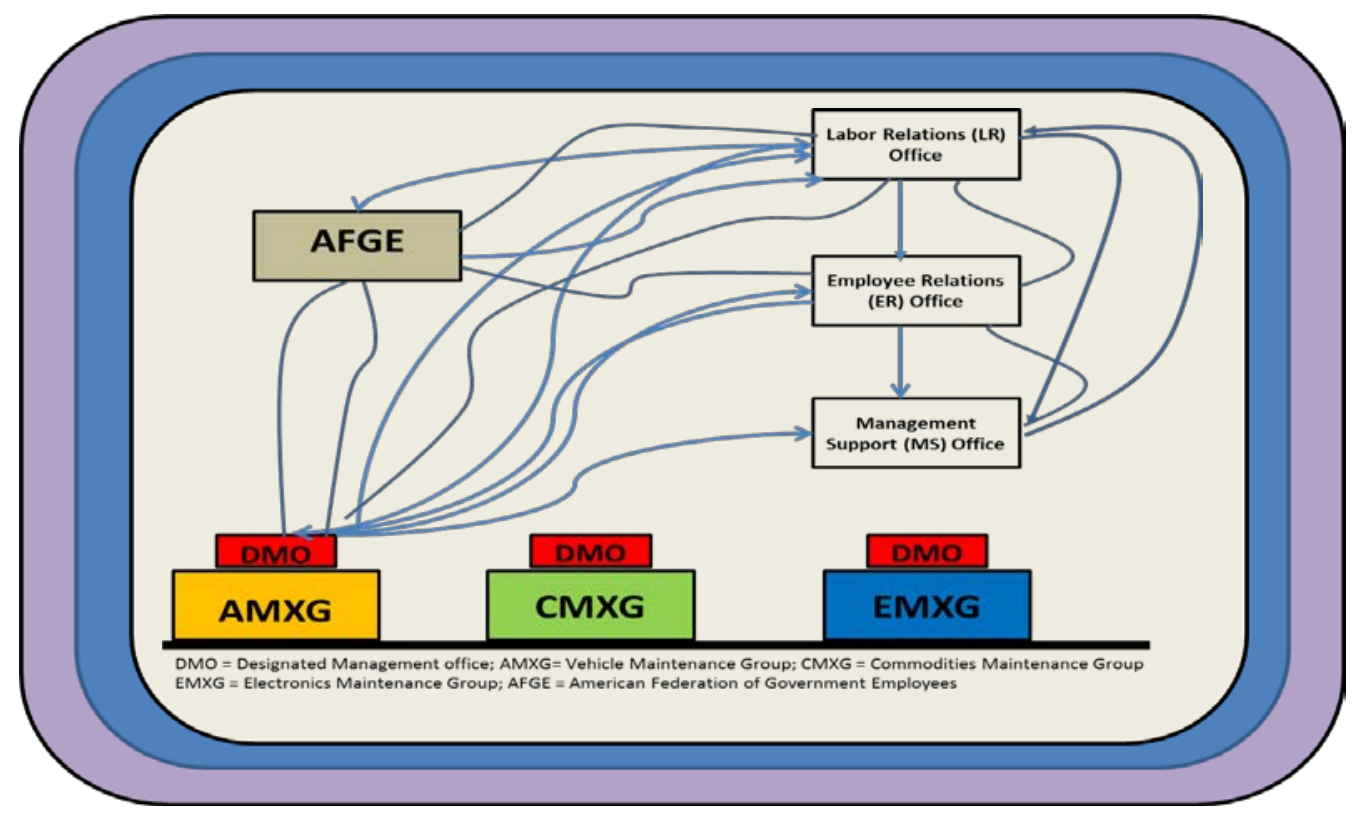


Figure 3: Service Cells

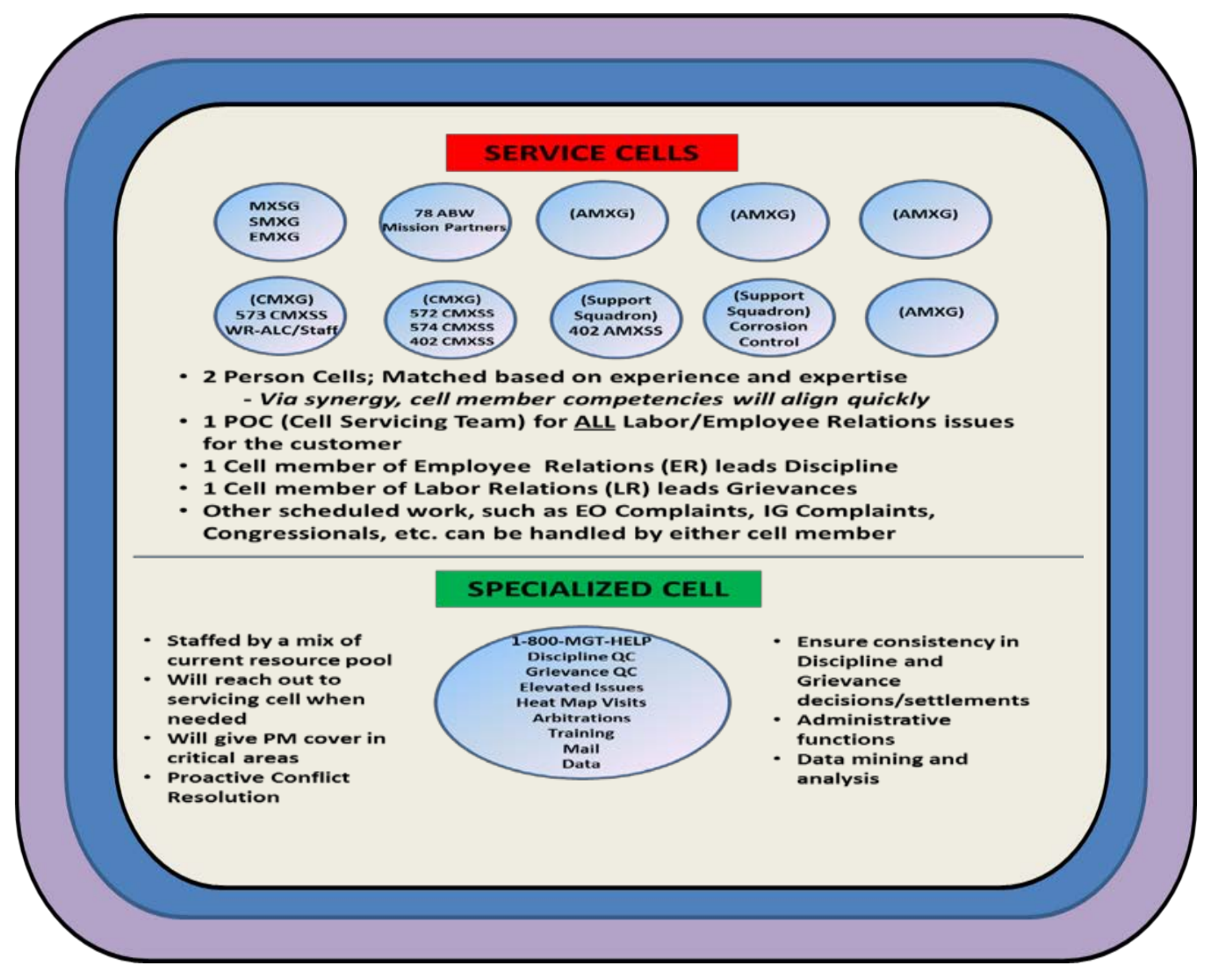


